\title{
Short Communication: Scoring of Digital Dermatitis During Milking as an Alternative to Scoring in a Hoof Trimming Chute
}

\author{
P. T. Thomsen,,${ }^{\star 1}$ I. C. Klaas, $†$ and K. Bach‡ \\ *University of Aarhus, Faculty of Agricultural Sciences, Department of Animal Health, Welfare and Nutrition, Tjele, Denmark \\ †University of Copenhagen, Faculty of Life Sciences, Department of Large Animal Sciences, Frederiksberg, Denmark \\ ‡Dyrlægerne Uni-Vet, Brørup, Denmark
}

\section{ABSTRACT}

Digital dermatitis is a serious problem in dairy production in many countries. In many settings, it is important to evaluate the digital dermatitis status of individual cows or an entire dairy herd. Such an evaluation has traditionally been done in a hoof trimming chute. An evaluation in the milking parlor can take place without disturbing the cows to a large extent, it can be done using less labor compared with an evaluation in a hoof trimming chute, and is cheaper than using a chute. The objective was to evaluate the sensitivity and specificity of a rapid screening method for digital dermatitis in the milking parlor, without using any specialized tools and taking approximately $15 \mathrm{~s} / \mathrm{cow}$. All lactating cows in 3 commercial Danish dairy herds were included. Cows were first scored for the presence of digital dermatitis during milking and the next day all cows were scored during hoof trimming. A 6-point nominal scoring system based on a visual inspection of the digital dermatitis lesions was used. For the analysis, the scores were dichotomized (digital dermatitis positive or digital dermatitis negative). Additionally, lesions were classified as small (diameter $\leq 2 \mathrm{~cm}$ ) or large (diameter $>2 \mathrm{~cm}$ ). Sensitivity and specificity were calculated using observations from the hoof trimming chute as the "gold standard" and observations during milking as the diagnostic test. Relatively large variation was found between herds with an overall sensitivity of 0.65 (95\% confidence interval: 0.59 to 0.72 ) and a specificity of 0.84 (0.81 to 0.87 ). The sensitivity increased to 0.69 (0.62 to 0.76 ), when only large lesions were assessed. The method has several advantages compared with evaluation in a chute and may be a useful tool in the daily hoof health management in dairy herds.

Key words: digital dermatitis, screening method, milking parlor, hoof trimming chute

Received May 9, 2008.

Accepted September 2, 2008.

${ }^{1}$ Corresponding author: PeterT.Thomsen@agrsci.dk
Digital dermatitis is a serious problem in dairy production in many countries. Since it was first described in 1974, the disease has been reported worldwide (Laven and Logue, 2006). Digital dermatitis might cause pain and lameness in infected cows, thus negatively affecting animal welfare (Bergsten, 1997; Rodriguez-Lainz et al., 1999; Almeida et al., 2007). It is debated whether or not digital dermatitis causes a reduction in milk production (Warnick et al., 2001; Cooke and Bennett, 2005; Losinger, 2006).

To assess herd prevalence of digital dermatitis and the effect of management and treatment strategies for digital dermatitis, it is important to be able to evaluate the digital dermatitis status of individual cows and entire dairy cattle herds. Such evaluations are relevant both in relation to research aimed at determining risk factors for digital dermatitis and for the individual dairy farmer in his or her day-to-day hoof health management. Traditionally, digital dermatitis status was evaluated during hoof trimming in a hoof trimming chute (Manske et al., 2002; Holzhauer et al., 2006; Thomsen et al., 2008). Some studies used an evaluation in the milking parlor (Rodriguez-Lainz et al., 1998; Laven, 1999). An evaluation in the milking parlor can take place without disturbing the cows to any large extent, it can be done using much less labor compared with an evaluation in a hoof trimming chute, and it is a much cheaper method. Additionally, more frequent evaluations can be done in the milking parlor as the method is not dependent on the presence of the hoof trimmer. All in all, there are several economic and practical advantages for using an evaluation in the milking parlor compared with a traditional evaluation in a chute. It is uncertain to what degree an evaluation in the milking parlor is valid. Rodriguez-Lainz et al. (1998) and Laven (1999) compared sensitivity and specificity of an evaluation in the milking parlor to an evaluation in a hoof trimming chute as the "gold standard." However, their methods are not very applicable under practical conditions. The procedure used by Rodriguez-Lainz et al. (1998) took approximately $2 \mathrm{~min} / \mathrm{cow}$ for the evaluation in 
Table 1. Scoring system for classification of digital dermatitis lesions used in a Danish study evaluating scoring during milking as an alternative to scoring in a hoof trimming chute (from Manske et al., 2002)

\begin{tabular}{ll}
\hline Score & Description \\
\hline 0 & No lesion \\
1 & Hyperemic area with erect pili \\
2 & Moist, exudative, and hyperemic area, with intact epidermis \\
3 & Exudative area, exposed corium, with no signs of healing \\
4 & Exposed corium, but in the process of healing, dried-up lesion \\
5 & Dark brown scab, completely or almost completely healed lesion \\
\hline
\end{tabular}

the milking parlor. That amount of time will inevitably slow down the milking process. Additionally, the period between the evaluation in the milking parlor and the subsequent evaluation in the hoof trimming chute was 1 to 5 wk. The "true" digital dermatitis status of cows may have changed during this time frame. Laven (1999) used a rigid borescope for the evaluation in the milking parlor and depended on a relatively expensive tool.

The objective was to evaluate the sensitivity and specificity of a rapid screening method for digital dermatitis in the milking parlor using no specialized tools and taking approximately $15 \mathrm{~s} /$ cow. In this way, the method could be applicable not only for research, but also in the daily hoof health management on commercial dairy farms as the milking process would only be minimally disturbed. Our hypothesis was that the screening method would have a high sensitivity and specificity and could be used instead of an evaluation in the hoof trimming chute.

The study included 3 commercial Danish dairy herds. Herds were selected using convenience sampling based on the inclusion criteria: loose-housing system, milking parlor, and a cooperative farmer. We did not want to include herds using automatic milking systems because an evaluation of the hooves in the milking robot was not straightforward (no fixed milking time and limited possibilities to evaluate the rear feet of the cow). All observations were made by 1 observer. Before the start the observer received training regarding the scoring of digital dermatitis during several herd visits. During these herd visits, the observer was trained by a veterinarian (second author) with several years of experience in scoring of digital dermatitis. The study took place in November and December 2007. A total of 393 cows were examined in 3 herds and used for evaluation of the scoring system $(75,161$, and 157 cows, respectively). The 3 study herds had 3 different types of milking parlors (herringbone, parallel, and carousel). All lactating cows in each herd were first observed during a routine milking. Rear legs of all cows were washed in the milking parlor using a water hose, each cow was identified using the ear tag, and all digital dermatitis lesions on rear legs were recorded using the scoring system de- scribed by Manske et al. (2002). The scoring system is presented in Table 1. The observer used a flashlight to ensure adequate light for the evaluation and a Dictaphone to record the scorings. Washing and examination of each cow lasted approximately $15 \mathrm{~s}$. The next day all lactating cows in the herd were examined during a routine hoof trimming in the hoof trimming chute. Again, all digital dermatitis lesions were recorded. Additionally, the observer used a ruler to measure the size (diameter in $\mathrm{cm}$ rounded to nearest $\mathrm{cm}$ ) of any lesions present. The total examination in the chute lasted approximately $1 \mathrm{~min} / \mathrm{cow}$. Each individual rear leg was treated as 1 observation and the number of observations used for the analysis equaled twice the number of cows examined. At the second examination (in the hoof trimming chute) the observer was blind to the result of the first examination.

Sensitivity and specificity were calculated using observations from the hoof trimming chute as the gold standard and the observations during milking as the diagnostic test. Sensitivity and specificity were calculated using the PROC FREQ procedure in SAS (version 9.1, SAS Institute Inc., Cary, NC). For the analysis, scores 1, 2, 3, 4, and 5 from Manske et al. (2002) were classified as digital dermatitis positive, and score 0 was classified as digital dermatitis negative. To evaluate the possible effect on sensitivity, specificity, or both, of differences in digital dermatitis lesion size, sensitivity and specificity were calculated for small and large lesions separately. Lesions $\leq 2 \mathrm{~cm}$ in diameter were classified as small and lesions $>2 \mathrm{~cm}$ were classified as large.

In total, there were 235 rear legs with digital dermatitis of 786 rear legs observed in the milking parlor and 226 rear legs with digital dermatitis of 786 rear legs in the hoof trimming chute. The prevalence of rear legs with digital dermatitis in the hoof trimming chute was $0.21,0.27$, and 0.34 , respectively, in the 3 herds. In total, $32.2 \%$ of digital dermatitis lesions were classified as small and $67.8 \%$ were classified as large. The distribution of lesion sizes is illustrated in Figure 1. Overall, large variation between herds was estimated for sensitivity and specificity $(0.65,95 \%$ confidence interval: 0.59 to $0.72 ; 0.84 ; 95 \%$ confidence interval: 0.81 


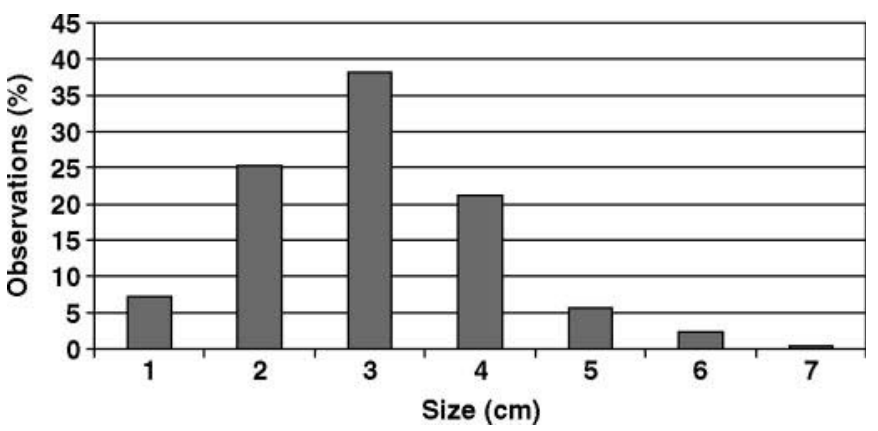

Figure 1. Distribution of sizes of digital dermatitis lesions on hind legs $(\mathrm{n}=226)$ when evaluating the validity of scoring of digital dermatitis during milking. The diameter of the lesions was measured in centimeters during hoof trimming and rounded to the nearest centimeter.

to 0.87 , respectively). Sensitivity and specificity for each herd and descriptive characteristics are in Table 2. When sensitivity and specificity were calculated for small and large lesions separately, sensitivity was 0.57 (0.45 to 0.69 ) and specificity was 0.84 (0.81 to 0.87 ) for small lesions, and sensitivity was 0.69 (0.62 to 0.76 ) and specificity was 0.84 (0.81 to 0.87 ) for large lesions.

Laven (1999) found a sensitivity of 0.85 and 0.79 and a specificity of 0.83 and 0.85 for right and left rear legs, respectively, using a rigid borescope in the milking parlor in 1 herd. Rodriguez-Lainz et al. (1998) found a sensitivity of 0.72 and a specificity of 0.99 using no tools in the milking parlor in 1 herd. In the present study, we found an overall sensitivity of 0.65 and a specificity of 0.84 . The sensitivity is lower than that in Laven (1999) and Rodriguez-Lainz et al. (1998). The specificity is comparable to that found by Laven (1999), but lower than that found by Rodriguez-Lainz et al. (1998). Still, the conditions under which the evaluation took place were not comparable. Laven (1999) used a relatively expensive borescope for the evaluation and Rodriguez-Lainz et al. (1998) used a much longer time for the evaluation of each individual cow. They used approximately $2 \mathrm{~min} / \mathrm{cow}$ compared with $15 \mathrm{~s} /$ cow in the present study. Therefore, we find the sensitivity and specificity of our method acceptable, especially if the method is used in situations where very precise estimates of the prevalence of digital dermatitis are not imperative. This may be the case if used in hoof health management in a dairy herd.

We generally obtained better results in herds 2 and 3 compared with herd 1 . This may be because of the additional experience of the observer in the last 2 herds or the physical conditions in these herds. Herd 1 had a herringbone milking parlor. In this type of milking parlor, the distance between the observer and one of the rear legs was relatively long because of the angle at which the cows were standing. In herds 2 and 3 , the distance between the observer and both rear legs was relatively short (parallel milking parlor and carousel with the cows standing with both rear legs very close to the observer). Several characteristics regarding the cows in different herds may have affected the sensitivity and specificity obtained in different herds. These characteristics include claw angle, depth of the heel, pastern and fetlock conformation, presence of heel horn erosions, and presence of interdigital dermatitis. All these factors may make the observation of digital dermatitis lesions more or less difficult and may have influenced sensitivity and specificity. Further investigations are needed in relation to these differences between herds. The washing of hooves with a water hose was generally sufficient to remove most of the manure on the hooves. In this way, manure contamination only very rarely impaired the ability to see any lesions present. Generally, the cleanliness of the hooves after cleaning did not differ between herds.

We found greater sensitivity when looking only at large digital dermatitis lesions compared with looking at small lesions only. This seems logical, because large lesions are easier to recognize compared with smaller lesions. We only looked at rear legs for 2 reasons: digital dermatitis is much more common on rear legs (Bergsten, 1997; Rodriguez-Lainz et al., 1999; van Amstel and Shearer, 2006) and the physical conditions in the milking parlors did not allow for the evaluation of lesions on front legs easily.

The sensitivity and specificity of the method used were, in most cases, too low for research purposes where precise estimates of the prevalence of digital dermatitis are needed. In this case, we would still recommend an evaluation in a hoof trimming chute. Alternatively, increased observation time per cow in the milking

Table 2. Descriptive characteristics, sensitivity, and specificity ( $95 \%$ confidence interval) for 3 herds in an evaluation of the validity of a scoring of digital dermatitis during milking

\begin{tabular}{llccc}
\hline Herd & Milking facility & Cows examined, $n$ & Sensitivity & Specificity \\
\hline 1 & Herringbone & 75 & $0.84(0.72$ to 0.97$)$ & $0.51(0.42$ to 0.60$)$ \\
2 & Parallel & 161 & $0.68(0.58$ to 0.78$)$ & $0.91(0.87$ to 0.94$)$ \\
3 & Carousel & 157 & $0.58(0.48$ to 0.67$)$ & $0.97(0.94$ to 0.99$)$ \\
\hline
\end{tabular}


parlor might be used. This would still be easier and less expensive compared with an evaluation in the hoof trimming chute. Nevertheless, the described screening method is valuable for a regular evaluation of digital dermatitis prevalence in a dairy herd and monitoring of its development over time. With frequent evaluations the prevalences could be used to estimate the incidence risk in the herd. The screening could be an important tool in herd health management if goals and thresholds are defined by the farmer (in cooperation with his or her consultant). In day-to-day hoof health management, the method could be used to identify cows with digital dermatitis for individual treatment. The method is much cheaper, easier, and quicker than an evaluation in a hoof trimming chute. After a limited amount of training, the farmer or a trained assistant may be able to do the evaluation during routine milkings. Milkers in the herds included in this study generally stated that the observer being present during milking did not disturb the milking process. It was not possible to use the described method in herds with automatic milking systems, but the method could be adapted to specific conditions in tie stall barns. A disadvantage of the method is that the hoof has to be observed at a different angle compared with an examination in a hoof trimming chute. This might mean that some lesions are missed. This was the case with lesions placed elsewhere than the most common site of the lesions on the plantar skin (van Amstel and Shearer, 2006). Still, we found only 9 legs (of a total of 226 legs with digital dermatitis) with lesions in other sites during the examination in the hoof trimming chute. Additionally, the leg of the cow was not fixed and the observer had only limited ability to palpate lesions for the presence of pain (because of the high risk of being kicked by the cow). A water jet might be used as an alternative way to evaluate the presence of pain. Holzhauer et al. (2007) found that pain was not present in all cases of digital dermatitis.

In conclusion, we found a relatively large variation between herds with an overall acceptable sensitivity and specificity of the described screening method for digital dermatitis. The method has several practical advantages compared with an evaluation in a hoof trimming chute: it is cheap, easy, and quick. Sensitivity and specificity may be too low for some research purposes, but the method may be useful in the daily hoof health management in dairy herds. The present study should be considered a pilot study, and further investigations are needed to evaluate differences in sensitivity and specificity between herds.

\section{ACKNOWLEDGMENTS}

Kurt Bach made all the observations during milking and hoof trimming as part of his final project as a veterinary student. Without his work this study would not have been possible. We wish to thank the farmers participating for their hospitality and interest. We greatly acknowledge the help from Annette Kjær Ersbøll (University of Copenhagen, Denmark) regarding statistical issues.

\section{REFERENCES}

Almeida, P. E., D. R. Mullineaux, W. Raphael, C. Wickens, and A. J. Zanella. 2007. Early detection of lameness in heifers with hairy heel warts using a pressure plate. Anim. Welf. 16:135-137.

Bergsten, C. 1997. Infectious diseases of the digits. Pages 89-100 in Lameness in Cattle. 3rd ed. P. R. Greenough, and A. D. Weaver, ed. W. B. Saunders Company, Philadelphia, PA.

Cooke, R. J., and R. M. Bennett. 2005. The costs and benefits of digital dermatitis control on UK dairy farms. Cattle Practice $13: 239-242$.

Holzhauer, M., C. J. M. Bartels, D. Döpfer, and G. van Schaik. 2007. Clinical course of digital dermatitis lesions in an endemically infected herd without preventive herd strategies. Vet. J. 177:222230.

Holzhauer, M., C. Hardenberg, C. J. M. Bartels, and K. Frankena. 2006. Herd- and cow-level prevalence of digital dermatitis in the Netherlands and associated risk factors. J. Dairy Sci. 89:580 588.

Laven, R. A. 1999. The environment and digital dermatitis. Cattle Practice 7:349-354.

Laven, R. A., and D. N. Logue. 2006. Review: Treatment strategies for digital dermatitis for the UK. Vet. J. 171:79-88.

Losinger, W. C. 2006. Economic impacts of reduced milk production associated with papillomatous digital dermatitis in dairy cows in the USA. J. Dairy Res. 73:244-256.

Manske, T., J. Hultgren, and C. Bergsten. 2002. Topical treatment of digital dermatitis associated with severe heel-horn erosion in a Swedish dairy herd. Prev. Vet. Med. 53:215-231.

Rodriguez-Lainz, A., P. Melendez-Retamal, D. W. Hird, and D. H. Read. 1998. Papillomatous digital dermatitis in Chilean dairies and evaluation of a screening method. Prev. Vet. Med. 37:197-207.

Rodriguez-Lainz, A., P. Melendez-Retamal, D. W. Hird, D. H. Read, and R. L. Walker. 1999. Farm- and host-level risk factors for papillomatous digital dermatitis in Chilean dairy cattle. Prev. Vet. Med. 42:87-97.

Thomsen, P. T., J. T. Sørensen, and A. K. Ersbøll. 2008. Evaluation of three commercial hoof-care products used in footbaths in Danish dairy herds. J. Dairy Sci. 91:1361-1365.

van Amstel, S. R., and J. Shearer. 2006. Infectious claw diseases. Pages 165-180 in Manual for Treatment and Control of Lameness in Cattle. Blackwell Publishing, Ames, IA.

Warnick, L. D., D. Janssen, C. L. Guard, and Y. T. Gröhn. 2001. The effect of lameness on milk production in dairy cows. J. Dairy Sci. 84:1988-1997. 